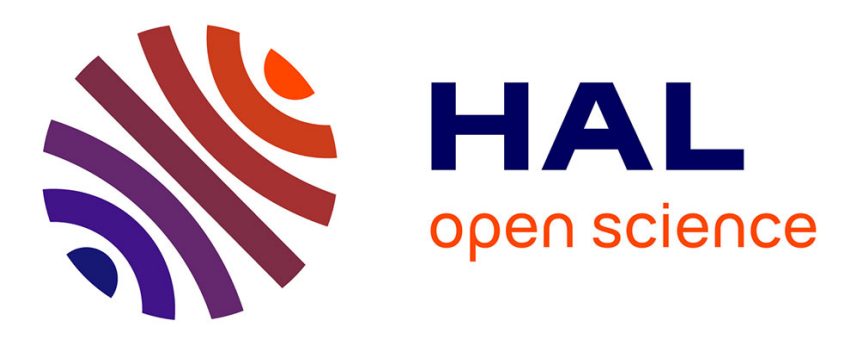

\title{
Faces and Thoughts: An Empathic Dairy
}

José Mennesson, Benjamin Allaert, Ioan Marius Bilasco, Nico van Der Aa, Alexandre A. J. Denis, Samuel Cruz-Lara

\section{To cite this version:}

José Mennesson, Benjamin Allaert, Ioan Marius Bilasco, Nico van Der Aa, Alexandre A. J. Denis, et al.. Faces and Thoughts: An Empathic Dairy. IEEE International Conference on Automatic Face and Gesture Recognition, IEEE, May 2015, Ljubljana, Slovenia. hal-01150212

\section{HAL Id: hal-01150212 \\ https://hal.science/hal-01150212}

Submitted on 29 Sep 2018

HAL is a multi-disciplinary open access archive for the deposit and dissemination of scientific research documents, whether they are published or not. The documents may come from teaching and research institutions in France or abroad, or from public or private research centers.
L'archive ouverte pluridisciplinaire HAL, est destinée au dépôt et à la diffusion de documents scientifiques de niveau recherche, publiés ou non, émanant des établissements d'enseignement et de recherche français ou étrangers, des laboratoires publics ou privés. 


\title{
Faces and Thoughts : an Empathic Dairy
}

\author{
José Mennesson $^{1}$, Benjamin Allaert ${ }^{1}$, Ioan Marius Bilasco ${ }^{1}$, Nico van der Aa ${ }^{2}$, Alexandre \\ Denis $^{3}$, Samuel Cruz-Lara ${ }^{3}$ \\ ${ }^{1}$ Laboratoire CRIStAL, University of Lille1, Lille, France \\ ${ }^{2}$ Noldus Information Technology BV, Wageningen, The Netherlands \\ ${ }^{3}$ Laboratoire LORIA, University of Lorraine, Vandoeuvre-lès-Nancy, France
}

\section{INTRODUCTION}

Many diary apps have been developed for an Android mobile device. Although most concentrate on securing the privacy and adding emoticons, only a few include automatic emotion measurements. This demo shows a new diary app including real-time multi-modal emotion measurements to capture the affective state of the user from the text provided and video images made. The emotion measurements from the Emotion from Face module, that analyzes images from the front camera [1], and the Emotion from Text module, that analyzes the text written by the user [2], are merged within the Emotion Fusion module to estimate the user's affective state more robustly. The app allows the user to have empathic feedback for each session.

\section{GLOBAL ARCHITECTURE}

The Empathic Diary App is an Android application which communicates with the different emotion measurement modules using different ways. The Emotion from Face module, which is embedded in the application using the Java Native Interface (JNI), is continuously extracting emotions from video images. The text is analyzed asynchronously by the Emotion from Text module on a remote server. The emotions extracted from text and video are sent asynchronously to the Emotion Fusion module using N-Linx, a flexible and scalable communication platform developed by Noldus Information Technology for communication between systems, which uses the AMQP implementation RabbitMQ as its core component.

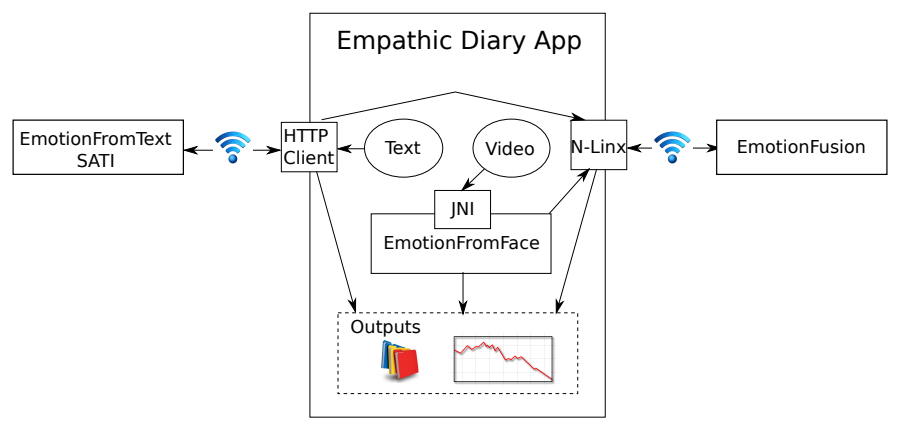

Fig. 1. Global architecture of the Empathic Diary App.

This work was supported by "Empathic Products", ITEA2 1105.
The Emotion from Text module includes the SATI API [3], which enables to perform Sentiment Analysis from Textual Information. The engine relies mostly on lexicons and syntactic rules for handling valence shifting phenomena. It is combined with a machine learning algorithm, and when trained on a Twitter corpus, it achieves a F-measure of $67.43 \%$ [2], amongst the best systems for this task. The API itself is accessed through HTTP GET requests.

The Emotion from Face module computes quality measures on images and enhances them to detect user face and eyes. If these ones are detected and image quality is sufficient, the face image is normalized and emotion metrics [1] including anger, happy and surprise are extracted.

Emotion measurements extracted from text and video can only be merged at the decision level as the emotion measurements are already done separately. The mean rule [4] is considered as one of the most accurate methods, i.e. for each emotion received by each modules, it takes the mean value. As output of the Emotion Fusion module, a weight for each type of emotions is returned to the application.

\section{EMPATHIC DIARY APP}

Besides the real-time emotion measurements, the Empathic Diary App is a diary app including the functionalities of data storage, taking pictures and giving summaries.
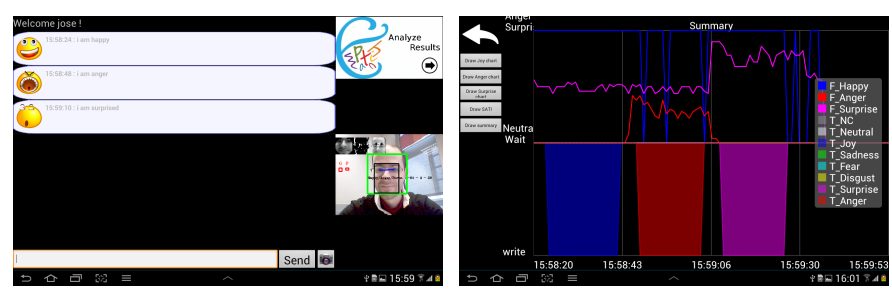

Fig. 2. Screenshots of the Empathic Diary App.

\section{REFERENCES}

[1] I. M. Bilasco, A. Lablack, A. Dahmane, T. Danisman, Analysing user visual implicit feedback in enhanced TV scenarios, Spontaneous Facial Behavior Analysis - ECCV Workshop, 2014, Zurich, Switzerland.

[2] A. Denis, S. Cruz-Lara, N. Bellalem, L. Bellalem. Synalp-Empathic: A Valence Shifting Hybrid System for Sentiment Analysis. In Proceedings of the 8th International Workshop on Semantic Evaluation (SemEval 2014), 2014, Dublin, Ireland.

[3] SATI API, http://talc2.loria.fr/empathic/

[4] F. Linggenfelser, J. Wagner and E. André, A systematic discussion of fusion techniques for multi-modal affect recognition tasks. In 13th Int. Conf. on Multimodal Interaction (ICMI'11), Alicante, Spain, 2011. 